\title{
EL PATRONAZGO EN LOS TIEMPOS DEL SISTEMA NACIONAL DE EMPLEO PÚBLICO (SINEP) DE LA APN DE LA REPÚBLICA ARGENTINA. NUEVOS ESCENARIOS DE UN LASTRE ATÁVICO
}

\author{
Diego Luxardo (*) \\ Universidad Nacional de Quilmes
}

\begin{abstract}
RESUMEN
Las dificultades con las que se han topado históricamente los intentos de introducir servicios civiles profesionales y meritocráticos en la Administración Pública Nacional (APN) de la República Argentina remiten al profundo arraigo del patronazgo. Pero este fenómeno, por su versatilidad adaptativa a los diversos marcos normativos que han procurado regular el ingreso a la APN en este país, no ha sido fácil de afrontar, ni de estimar, ni siquiera de detectar. El presente trabajo procura responder a esta inquietud, en el escenario que abre la implementación del sistema de concursos contemplado en el actual (y principal) sistema de empleo público de la APN argentina (el SINEP). Para esto propone una nueva metodología, que indaga dentro de un proceso de concursos en particular, procurando estimar el grado de apertura de la administración pública a la ciudadanía, y, por contraposición, su nivel de patronazgo. Como surge de la presente investigación, los mecanismos abiertos, competitivos y meritocráticos de ingreso a la gestión pública en este ámbito aun distan de gozar de plena vigencia.
\end{abstract}

\section{PALABRAS CLAVE:}

servicio civil, patronazgo, nivel de apertura de la AP a la ciudadanía.

\footnotetext{
(•) E-mail: diegoluxardo@gmail.com
}

\section{ABSTRACT}

The difficulties with which the attempts to introduce professional and meritocratic civil services in the National Public Administration (APN) of the Argentine Republic have historically met refer to the deep roots of patronage. But this phenomenon, due to its adaptive versatility to the different normative frameworks that have tried to regulate the entry to the APN in this country, has not been easy to face, nor to estimate, nor even to detect. The present work seeks to respond to this concern, in the scenario that opens the implementation of the competition system contemplated in the current (and main) public employment system of the Argentine APN (the SINEP). For this purpose, it proposes a new methodology, which investigates in a process of competitions in particular, trying to estimate the degree of openness of the public administration to the citizenship, and, by contrast, its level of patronage. As it emerges from this research, the open, competitive and meritocratic mechanisms of admission to public management in this area are still far from being fully valid.

\section{KEY WORDS:}

civil service, patronage, level of openness of the public administration to the citizens.

RECEPCIÓN: $18 / 02 / 19$

ACEPTACIÓN FINAL: 03/07/19 


\section{INTRODUCCIÓN ${ }^{1}$}

Los procesos de establecimiento de los servicios civiles no han sido, en ningún caso histórico, lineales, ni han derivado directa y automáticamente de la sanción de una norma. Los avances han sido graduales, intermitentes, no exentos de retrocesos, atravesados por luchas políticas, negociaciones y resistencias, circunstancia agravada, a su vez, en aquellos países cuyos procesos de universalización del voto y surgimiento de partidos de masas precedieron a la consolidación de estructuras burocráticas profesionales. En estos casos, las burocracias se mostraron como un terreno propicio para la colonización del aparato estatal por parte de los nacientes partidos políticos (Schedler, 2004).

Esta fue la situación de América Latina en general, y de la República Argentina en particular. La dificultad de la institucionalización plena de los servicios civiles en esta región remite al profundo arraigo del patronazgo en las burocracias estatales, el cual explica, en gran medida, el elevado nivel de politización de estas estructuras, rasgo que socavó en buena medida la eficacia de las reformas tendientes a profesionalizarlas, a través de la introducción de criterios meritocráticos de selección y promoción.

Como se expondrá en el desarrollo del presente trabajo, a través de algunas definiciones y un breve repaso histórico, el arraigo del patronazgo ha dejado 
sus huellas en los intentos de implementar servicios civiles en la APN de este país en los últimos 30 años. Esto explica, en gran medida, la suspensión de los concursos del servicio civil anterior al vigente, el Sistema Nacional para la Administración Pública o SINAPA (Decreto No 993, del año 1991), y la proliferación de las modalidades contractuales flexibles y transitorias en los años posteriores.

Pero la introducción del nuevo sistema de empleo público, el Sistema Nacional de Empleo Público (SINEP), Decreto No 2098, del año 2008, abrió un escenario distinto, que en principio parecía dejar atrás la situación de irregularidad mencionada. Como pretende mostrar la presente investigación, también en este nuevo escenario pueden advertirse claros indicios de la reaparición de esta "atávica" práctica, que amenaza con socavar dicho sistema. Para fundamentar esta apreciación, y estimar su alcance, se proveerá una nueva metodología, encarnada en la categoría de nivel de apertura de la AP a la ciudadanía. Ésta permite indagar al interior de un proceso de concursos, detectando situaciones que pueden considerarse vinculadas al fenómeno en cuestión, y por ende, corroborando su arraigo.

\section{ALGUNAS PRECISIONES CONCEPTUALES SOBRE EL PATRONAZGO}

¿Qué es el patronazgo? El patronazgo constituye la vulneración de un orden o sistema, más precisamente, de un aspecto específico de éste. Por lo tanto, debe preceder a su definición la comprensión de ese orden y el aspecto que resulta vulnerado.

Como se adelantó, ese orden está dado por el servicio civil. Tal como lo define Longo (2006: 4-5), éste es "el sistema de gestión del empleo público y los recursos humanos adscritos al servicio de las organizaciones públicas, existente en una realidad nacional determinada". Se compone, siguiendo a este autor, de un "conjunto de arreglos institucionales mediante los que se articulan y gestionan el empleo público y las personas que integran éste", entre los que se cuentan las normas, estructuras organizativas, procedimientos formales, prácticas establecidas e informales, pautas culturales, políticas, etc. dirigidos a garantizar la gestión adecuada de los recursos humanos, con el fin de lograr una administración pública profesional y eficaz.

Pero no debe confundirse servicio civil con el marco jurídico que lo regula. Si bien este último es un elemento constitutivo del primero, un servicio civil comprende las prácticas efectivas en la gestión de los RRHH, más allá de su grado de adecuación a ese conjunto de normas. De hecho, la tensión entre 
el intento de implementar servicios civiles profesionales y el profundo arraigo del patronazgo ha tendido a generar una suerte de "brecha» entre el sistema formal (los marcos normativos e instituciones formales), y prácticas informales apenas afectadas por este sistema. Para muchos autores en la materia (Grindle, 147-148; Longo, 2006: 576; Ramió y Salvador, 2005: 104; Oszlak, 1997: 1; lacoviello, 2006: 542), este rasgo representa la principal debilidad de los servicios civiles de la región.

Signados en gran medida por su origen, que remite al surgimiento de los regímenes constitucionales de Europa y América del Norte hacia fines de siglo XVIII y comienzos deI XIX, y bajo el influjo de los principios políticos proclamados por la ilustración, los servicios civiles se cimentaron en torno a dos grandes valores: la igualdad (el principio de igualdad de oportunidades) y el mérito o idoneidad ${ }^{2}$. Éstos han sido, hasta nuestros días, los pilares de los servicios civiles en general.

En el caso de la APN de la República Argentina ${ }^{3}$, tanto en la Ley Marco de Regulación de Empleo Público Nacional № 25.164 (Ley de Empleo Público) del año 1999, como en su reglamentación (Decreto No 1421/02), el Convenio Colectivo de Trabajo General de la APN (CCTG, Decreto No 214/06) y el Sistema Nacional de Empleo Público o SINEP (Decreto No 2098/2008), se introduce ambos valores en forma conjunta e interdependiente: para acceder a un cargo público se debe garantizar la efectiva igualdad de oportunidades en la evaluación de las condiciones de conducta e idoneidad.

La distinción de estos valores es determinante para comprender la "esencia" del patronazgo, que no siempre resulta evidente. Éste constituye una vulneración al primero de estos valores, el principio de igualdad de oportunidades, y no necesariamente atenta contra el principio de idoneidad. Suele hacerlo, pero ese rasgo es contingente. Grindle lo define como una práctica informal por la cual se realizan designaciones discrecionales, por razones políticas o personales, en cargos no electivos (Grindle, 2012). Como puede apreciarse, discrecionalidad, sin alusión a idoneidad (prueba de esto, como ha mostrado Scherlis (2009), es la existencia de patronazgo incluso por razones "técnicas", es decir, por la necesidad de cubrir cargos con personal idóneo en áreas técnicas en plazos no compatibles con los insumidos por un proceso de concursos). Posteriormente se verá cómo esto se traduce, a partir de los marcos normativos que regulan ciertas modalidades contractuales, en cauces de acción bastante definidos; estas modalidades encarnarán una de las expresiones actuales de este fenómeno. 


\section{PROCEDIMIENTOS DE INGRESO:}

\section{EL SINEP Y LAS MODALIDADES CONTRACTUALES TRANSITORIAS}

La estructuración de los servicios civiles en torno a estos dos valores fundamentales hizo que la inmensa mayoría de éstos, en su afán de hacer efectivos a ambos en relación a las condiciones de ingreso a la AP, desarrollara un mecanismo (o conjunto de procedimientos) determinado: el proceso de concursos. Éstos constituyen un mecanismo para la cobertura de cargos "no políticos" vacantes (generalmente, como en el caso del SINEP, los de carrera o planta permanente), a través de una competencia entre aspirantes a los mismos, procurando garantizar, por un lado, la idoneidad requerida para el cargo, y por otro, una efectiva igualdad de oportunidades entre estos competidores.

Tal es el caso del servicio civil aquí analizado (el SINEP), el cual establecerá que los procesos de selección se lleven a cabo «mediante concursos de oposición y antecedentes" para evaluar idoneidad y competencias laborales, arrojando un orden de mérito o terna del que surgirán los ganadores (Decreto № 2098, art. 34). Este Convenio regulará “los procesos de selección para la cobertura de cargos vacantes de la planta permanente de las unidades organizativas cuyo personal está comprendido por el SINEP..." (art. $1^{\circ}$ de la Resolución de la Secretaría de Gestión Pública № 39/10). Los procedimientos que procuran hacer efectivos estos dos valores abundan.

Respecto a la idoneidad, el SINEP despliega un complejo proceso de evaluación estructurado en cuatro etapas (art. 35): evaluación de antecedentes curriculares y laborales, evaluación técnica para acreditar conocimientos, habilidades y capacidades, evaluación mediante entrevista laboral y evaluación del perfil psicológico. Las mismas deben ser llevadas a cabo por Comités de Selección en cuya composición deben incluir profesionales idóneos en la materia a considerar (art. 39).

En cuanto a la igualdad de oportunidades, también se establecen numerosos resguardos. Ante todo, la exigencia de difusión de las convocatorias, por medios de difusión masiva (art. 44), publicación en el Boletín Oficial, en la Cartelera Pública Central de Ofertas de empleo público de la Jefatura de Gabinete de Ministros, en Carteleras disponibles en cada Jurisdicción u organismo descentralizado (art. 46), etc.. En la instancia de las evaluaciones, exige que al menos el $50 \%$ de los miembros de los Comités de Selección no se hallen vinculados "laboral o contractualmente bajo cualquier modalidad con las jurisdicciones u organismos descentralizados" en los cuales se desarrollan los concursos (Resolución de la Secretaría de Gestión Pública № 39/10, art 29). Introduce incluso la posibilidad de abrir a la supervisión del proceso de 
evaluación a distintas organizaciones de la sociedad civil ("organizaciones no gubernamentales u otras personas jurídicas sin fines de lucro»), permitiéndoles postular un veedor ante el Comité de Selección (art. 38 del SINEP). En fin, estas y otras garantías procuran efectivizar los principios en cuestión.

Ahora bien, existiendo este sofisticado sistema de ingreso, ¿por qué la situación no está, definitivamente, encaminada hacia su resolución? La respuesta a este interrogante nos remite a la historia de este proceso, cómo fue configurándose, las circunstancias en torno al establecimiento del SINEP, y, fundamentalmente, la suerte que corrió su predecesor, el Sistema Nacional para la Administración Pública (SINAPA), sancionado en el año 1991.

Similares en numerosos aspectos, el SINAPA también suponía un proceso de concursos para el ingreso y la promoción dentro del sistema de carrera, los cuales comenzaron a implementarse a partir de aquel año. Sin embargo, pocos años después (1995), junto a este sistema de empleo surgió otra modalidad contractual, que suponía otro mecanismo de ingreso a la APN. Así fue como con la sanción de la Ley № 24.447/95 y el Decreto № 92/95 (amparándose en el Art. 81 de la Ley Complementaria Permanente del Presupuesto Nacional No 11.672), se instrumentó un régimen de locación de servicios personales, que posibilitaba la incorporación de personal evitando los procedimientos requeridos por el sistema de carrera. Las razones aducidas para su introducción apelaban al carácter transitorio de ciertas tareas, y la urgencia por cubrir ciertas funciones técnicas específicas. Lo cierto es que, por otra parte, estas contrataciones permitían eludir las exigencias establecidas por el sistema de carrera (posteriormente se brindarán mayores detalles al respecto). Ese mismo año los concursos fueron interrumpidos. Cuatro años después (1999) se oficializó la suspensión de los concursos (Decreto $N^{\circ} 455$, art. $4^{\circ}$ ), ante la inminencia del cambio de gobierno, rumbo que se convalidó al año siguiente con la prohibición de la cobertura de cargos vacantes en la planta permanente ("congelamientos") de la ley de Presupuesto Nacional (Ley 25.237, art. 22). En el año 2001 se sancionaría el Decreto № 1.184, prolongando y expandiendo el régimen de locación de servicios personales, práctica que se reiteraría y diversificaría algunos años después con el Decreto № 2345 del año 2008 (actualmente se rigen con el Decreto $N^{0} 735 / 16$ ). Así fue como otro tipo de modalidades contractuales se impuso y acabó por dejar sin efecto al SINAPA.

Pero simultáneamente a este proceso de creciente irregularidad en el empleo público, y en buena medida a raíz de las presiones ejercidas por los sindicatos, comenzarían las acciones para tratar de revertir esta situación. En forma paralela a la suspensión de los concursos (año 1999) se sancionó la 
Ley de Empleo Público (Ley No 25.164), cuya instrumentación se produjo tres años después, con el Decreto No 1421/02.

Sin embargo, esta voluntad de regularizar el empleo público presentaba sus dificultades. Por un lado, existía un número creciente de contratados (hacia comienzos del año 2005, en el Poder Ejecutivo Nacional, superaban los 20 mil $\operatorname{casos}^{4}$ ), respecto a quienes la extensión por tiempo indeterminado de su condición transitoria dejaba traslucir un vínculo laboral permanente. Pero, por otra parte, el marco normativo impedía resoluciones directas o inmediatas, a través de una simple decisión política. La Ley de Empleo Público era taxativa al respecto: vedaba el traspaso directo de los contratados a la planta (véase su art. 6, el art. 8 del Decreto Nro. 1421/02, art. 13 del Decreto No 214/06). Por esta razón se apeló a una figura de estabilidad intermedia, pero que reconocía la relación de dependencia laboral, contemplada en el Decreto $N^{\circ}$ 1421/02: las contrataciones transitorias del Art. 9 de la Ley de Empleo Público (contrataciones transitorias Art. 9). De este modo, a partir del año 2005, con el Decreto No 707/05, se inicia el traspaso, gradual pero masivo, de las contrataciones sin relación de dependencia (locación de servicios) a esta otra modalidad transitoria. Los Decretos № 2031/06 y 480/08 continuarían con ese traspaso. Esto significaba un claro avance en materia de derechos laborales y previsional. En el año 2006 el Convenio Colectivo de Trabajo General, Decreto № 214/06, vendría a reforzar esta política (de regularización), fijando un tope del $15 \%$ a las contrataciones a través de las modalidades contractuales transitorias (art. 156). En el año 2008 se sancionaría el marco normativo del nuevo servicio civil: el Decreto No 2098/08 o SINEP. Éste establecía un sistema de concursos, análogo al del SINAPA, para el acceso a los cargos vacantes de la planta permanente de la APN que se hallaba bajo su órbita (para precisar la extensión de esta cobertura véase Nota 3).

Esta política de regularización, en términos generales, arrojó algunos resultados positivos. Entre los años 2002 y 2008 los contratados sin relación de dependencia (Decreto No 1184/01) pasaron de ser 14.555 a 2.725, frente a las contrataciones a través del Decreto No 1421/02 (con relación de dependencia), que incrementaron su número de 90 a 26.037 (Salas, 2010). Pero en relación a la dimensión analizada en la presente investigación, los requisitos de ingreso a la AP, este traspaso de una modalidad contractual a otra, ¿qué significaba? Como se verá, no demasiado.

Más allá de la importante diferencia señalada entre estas dos modalidades contractuales transitorias (respecto al reconocimiento de la relación de dependencia laboral), en relación a sus respectivos mecanismos de ingreso 
o requisitos de contratación ambas coinciden en un aspecto fundamental: únicamente establecen exigencias en relación a la idoneidad, pero no definen ningún procedimiento de selección que garantice una efectiva igualdad de oportunidades en la competencia por acceder a un cargo vacante. Esto se comprueba al repasar la normativa que establece estos procedimientos ${ }^{5}$, entre cuyas exigencias figuran la justificación del titular de la jurisdicción sobre la necesidad de cobertura de un cargo vacante, la definición del perfil de ese cargo, con la descripción de las tareas, y, por último, la acreditación del cumplimiento de estos requisitos para su cobertura.

A diferencia del sistema de concursos, como el que establece el SINEP, a través del cual se desarrolla una competencia regulada entre aspirantes a cubrir los cargos vacantes, resguardando condiciones de publicidad, transparencia e imparcialidad, las contrataciones flexibles y transitorias (con y sin relación de dependencia) carecen de aquellos procedimientos que pueden hacer efectiva esa igualdad de oportunidades. No requieren la difusión de esas convocatorias, con la debida antelación, especificando medios y ámbitos, no exigen la presencia de un Comité de Selección cuyos integrantes sean, en un porcentaje establecido, externos al organismo en el que se hallan las vacantes a cubrir, etc. Pero fundamentalmente, no establecen una competencia abierta, transparente y regulada, en la cual se comparan los distintos elementos que componen la idoneidad, principalmente un examen técnico que equipara considerablemente las condiciones entre competidores.

En el mejor de los casos, estas modalidades contractuales transitorias emplean un sistema de selección por "ternas" de postulantes, elección que recae, en última instancia, en la autoridad convocante. Un mecanismo claramente más vulnerable en cuanto a su difusión y a las apreciaciones personales en esa elección. La vaguedad o debilidad de estos procedimientos se traduce, inevitablemente, en márgenes más elevados de discrecionalidad en las contrataciones.

Si se retoma la definición de patronazgo (discrecionalidad en la designación de cargos no electivos), la conclusión se impone: estas contrataciones constituyen la principal forma que ha adoptado el patronazgo hasta nuestros días. Existe un amplio consenso bibliográfico respecto a la "vulnerabilidad" de estas modalidades contractuales (flexibles y/o transitorias), y a su predominio como mecanismo de ingreso, desplazando los procedimientos establecidos por el sistema de carrera (Ferraro, 2006, Scherlis, 2009, 2012 y 2013; López y Zeller, 2010; lacoviello, Pando y Llano, 2013 y 2015; Iacoviello y Llano, 2015; Salas y Wegman, 2014; etc.). 


\section{IMPLEMENTACión dE LOS CONCURSOS Y ESTIMACIŌN DEL PATRONAZGo}

Sin embargo, pareciera existir un punto de inflexión en esta historia, hacia el año 2010, cuando comienza a implementarse el sistema de concursos contemplado en el SINEP ${ }^{6}$. Desde luego, esa implementación distaba y aún dista mucho de ser plena, y ha convivido, hasta aquí, con las rémoras del pasado (las contrataciones directas). Pero en términos generales, la implementación de este sistema abre un nuevo escenario que promete resolver el problema de fondo (la discrecionalidad en los ingresos). Esa es la conclusión que extraen algunos trabajos con un sesgo "formalista o normativista" (Salas y Wegman, 2014). Pero incluso cuando se considera las metodologías empleadas por otros autores para estimar el patronazgo, puede verse cómo en este nuevo escenario, buena parte de las mismas pierde su eficacia.

Tal es el caso de Ferraro (2006), quien basándose en la distinción mencionada entre los mecanismos de ingreso del sistema de carrera y los de las contrataciones por fuera del mismo (en aquel entonces sólo existían las flexibles), basa esa estimación en el número de contrataciones de uno y otras. Claramente la implementación del sistema de concursos socavaría la efectividad de esta metodología. Otros autores, han empleado métodos más indirectos. Gordín, 2001; Calvo, 2014; Remmer, 2007, asimilaron patronazgo y gasto salarial. Considerando la definición presentada de patronazgo (discrecionalidad en el ingreso a la AP), su vínculo con la masa salarial no deja de resultar bastante débil e indirecto. Pasa por alto el hecho de que el incremento del gasto salarial puede obedecer a diversas razones, como la incorporación de personal para el desempeño de nuevas funciones. Otros autores, como es el caso de Scherlis (2005), apelaron a una combinación del tamaño del empleo público y el nivel de afiliación partidaria para establecer esa magnitud. La debilidad de esta posición estriba en que reduce el patronazgo a su versión "políticopartidaria", desconociendo otras facetas de este fenómeno, como aquellas que lo vinculan a los sindicatos o a la misma burocracia. Por último, este mismo autor, en un trabajo posterior (Scherlis, 2009), apeló a la construcción de índices sobre la base de entrevistas a los actores clave de la APN argentina, entre los que se incluía a autoridades políticas, personal de cargos directivos, delegados sindicales, técnicos, etc. (en sintonía con esta línea, Kopecky et al. (2008, 2011, 2012) construirá un Índice de Patronazgo Partidario). A esta metodología cabe poco que objetar, aunque, como se verá con posterioridad, puede enriquecérsela sustancialmente (además, el trabajo realizado con esta metodología es previo a la incorporación de los concursos). En definitiva, todo 
parece indicar que la implementación de los concursos vuelve obsoleta, en cierta medida, la mayor parte de estas metodologías.

Sin embargo, y como se dijo, la efectiva vigencia de un sistema de carrera, con su respectivo mecanismo de ingreso a través de concursos, no suele ser un proceso lineal. La regularidad que pretende imponer toda norma se asienta sobre las irregularidades del terreno, erosionado por las prácticas efectivas que configuraron esa esfera de la realidad. De aquí la idea de "arraigo" del patronazgo. Para comprender el curso que tomarían las cosas (y entrever el que, de aquí en más, puede llegar a prevalecer) debe considerarse, por un lado, ese punto de partida, y por otro, las características del marco normativo en cuestión, fundamentalmente el instrumento que éste brindó (y brinda) para regularizar lo dado y regular, de aquí en más, esta dimensión de los servicios civiles.

Del punto de partida se ha hablado: esa situación de creciente "irregularidad" en el empleo público, producto de años de contrataciones transitorias, que con el transcurso del tiempo se hicieron permanentes, y de la imposibilidad de su traspaso directo a la planta permanente. En cuanto al marco normativo, el instrumento que éste ofrecía para regularizar esta situación era el sistema de concursos. De sus principales rasgos se infiere buena parte del desenlace de ese proceso. Como su nombre lo indica, éste no es, estrictamente hablando, un sistema de ingreso a la APN, sino un sistema de cobertura de cargos de la planta permanente. Esta diferencia no es menor, implica que, junto a la regulación del ingreso, cumple otras dos funciones. La primera, incluida en el corpus central de la normativa que regula la materia (Resolución de la Secretaría de Gestión Pública №39/10, Anexo I, art. 1), está dada por la promoción o ascenso de nivel escalafonario o de Agrupamiento para los integrantes del sistema de carrera. La segunda función, que ha gozado de una difusión muy inferior, es decisiva para comprender la fase posterior del proceso de regularización del empleo público. Si bien es omitida en ese corpus normativo (ni el Decreto № 2098/08 ni la Resolución de la Secretaría de Gestión Pública № 39/10 hacen alusión a ella), fue reconocida, indirectamente, en normas de menor rango, sujetas a situaciones coyunturales ${ }^{7}$ : hablamos del cambio de modalidad contractual o regularización; o sea, el traspaso del personal contratado bajo modalidades contractuales por tiempo determinado (transitorias y flexibles) a la planta permanente. Esta función era la que brindaba la posibilidad de llevar a cabo esa regularización.

Como se desprende de lo expuesto, todo proceso de concursos constituye, simultáneamente, un medio de: 
- ingreso a la APN,

- promoción dentro de ella, y

- regularización o traspaso de contrataciones transitorias a la planta permanente.

Por lo tanto, la implementación de este sistema implica establecer, abiertamente o por omisión, el peso que se atribuirá a cada una de estas tres funciones. ¿Y por qué es tan relevante establecer ese peso? Porque detrás de cada función hay un sector cuyos intereses las normas (que regulan esta materia) pretenden contemplar.

- Las promociones atañen a los integrantes de la planta permanente,

- las regularizaciones, a quienes pertenecen a la AP bajo otras modalidades contractuales (transitorias).

- Y los ingresos, como puede inferirse, a la ciudadanía en su conjunto (principalmente aquel sector con la capacidad y aspiración de acceder a un cargo).

En el contexto de implementación de una política de regularización del empleo público adquiere un valor fundamental establecer el alcance de estas funciones ya que implica que los intereses de los sectores involucrados en este proceso serán sopesados y considerados equitativamente (al menos, dentro de un equilibrio razonable). Un reducido porcentaje de ingresos representaría un importante indicio de la existencia de una decisión deliberada de "cerrar" los concursos, volviéndolos mayoritariamente un mecanismo de promoción dentro del sistema de carrera, o de regularización del personal incorporado transitoriamente, en detrimento de su función como mecanismo de ingreso a la APN. Esto supondría favorecer a determinados sectores (en este caso, a quienes ya pertenecen a la APN, tanto de planta como contratados), en desmedro de otros (la ciudadanía externa a la APN, cuyo interés general genuino solo puede estar orientado hacia una competencia abierta, en igualdad de condiciones, por acceder a los cargos a ocupar).

En un escenario de proliferación de modalidades contractuales cuyos requisitos de ingreso son altamente vulnerables a la discrecionalidad (de aquí su estrecho vínculo con el patronazgo), únicamente los ingresos a través de los concursos gozan de una "fuerte presunción" de ausencia de patronazgo, es decir, de garantía de una efectiva igualdad de oportunidades. Este es, según postula el presente trabajo, el mayor grado de precisión que puede alcanzarse en la estimación de este fenómeno. Por esta razón, si bien es comprensible 
la voluntad de regularizar determinadas situaciones, es fundamental, a la vez, garantizar un número razonable de ingresos. Y para eso, previamente, hay que poder detectarlos. Esta inquietud, en torno a la posibilidad de detectar los ingresos en el sistema de concursos, y estimar su peso en relación al total de los cargos concursados, contribuyó a forjar la categoría de univel de apertura de la AP a la ciudadanía" (nivel de apertura), que se desarrollará a continuación.

\section{5 el NIVEL de APERTURA de LA AP A LA CIUDAdANÍA}

Si bien reformulado con un contenido específico, este concepto reconoce un antecedente fundamental en la distinción introducida por Dussauge Laguna (2005) entre modelos de senvicio civil de carrera y de empleo. Los primeros, los servicios civiles de carrera, poseen un carácter "cerrado", por el cual el ingreso de los nuevos agentes se realiza, si bien a través de concursos abiertos, casi exclusivamente en los niveles iniciales, en la "base» de la estructura organizacional. Esto hace que los puestos intermedios y superiores sólo sean accesibles a quienes ya pertenecen al servicio civil. Por el contrario, el carácter «abierto" de los servicios civiles de empleo reside en que habilitan el ingreso en cualquier nivel de la estructura organizacional. Los cargos vacantes a ser ocupados, en todos los niveles jerárquicos, se abren a la competencia para el público en general.

En relación a este aspecto, el SINEP podría considerarse un sistema «híbrido" ${ }^{8}$, si bien tiene una clara afinidad con los sistemas de empleo, resguardando (formalmente) un elevado nivel de apertura a la ciudadanía, en su art. 31 permite "reservar o cerrar" hasta el $30 \%$ de los cargos cuya cobertura debe someterse a un sistema de selección abierto (convocatoria Abierta), para la competencia entre aquéllos que ya pertenecen a dicho sistema de empleo (las convocatorias reservadas para integrantes de dicho sistema son las convocatoria Generales). En este sentido, el sistema anterior, el SINAPA, se hallaba más próximo a los sistemas de carrera, ya que admitía, además de las convocatorias Abiertas y Generales, las "Internas", que se reservaban exclusivamente para los integrantes del organismo público en el cual se hallaban los cargos a cubrir. Esta diferencia es particularmente significativa ya que pone de manifiesto que en la transición de un sistema a otro (de SINAPA a SINEP) existió un claro designio de lograr una mayor apertura a la ciudadanía, reduciendo los cargos reservados a los integrantes de la APN.

Ahora bien, la noción de apertura hasta aquí expuesta es estrictamente "formal»: basta con recurrir a la normativa para conocer su alcance. Pero 
algo muy distinto es el nivel de apertura "real», el que acaba dándose en los hechos. Éste último requiere indagar dentro del proceso de concursos, más específicamente, entre sus ganadores (los que obtuvieron el cargo concursado). Teniendo en cuenta las tres funciones mencionadas (ingresos, promociones y regularizaciones), éstos pueden clasificarse en tres categorías:

- Los efectivamente ingresantes a la APN

- Los (ya) integrantes de la planta permanente

- Los integrantes de la APN bajo otras modalidades contractuales (transitorias).

La categoría de "nivel de apertura" estima el peso del primero de estos grupos. Éste se compone de aquellos casos en los cuales el ganador del mismo, al momento de concursar, no se hallaba vinculado contractualmente (de modo permanente o transitorio) a la APN (en dicho organismo u otro), ni registraba antecedentes recientes de contratación en ésta. Esta variable estima la proporción de ingresos en relación al total de los cargos concursados, y a partir de esto, la distancia que media con respecto al nivel de apertura "formal» (establecido en la normativa), detectando situaciones de apartamiento sistemático o generalizado de lo que ésta, se supone, pretende resguardar (el "espíritu de la norma»).

\section{PRESENTACIŌN DEL CASO INVESTIGAdO}

El caso elegido para la aplicación de la nueva metodología fue un proceso de concursos en particular, realizado en la Administración Central del Ministerio de Trabajo, Empleo y Seguridad Social (hoy Ministerio de Producción y Trabajo) durante el año 2015.

El organismo se escogió por su carácter paradigmático de todas las transformaciones expuestas: la implementación del SINAPA, la introducción de contrataciones flexibles, el traspaso a las transitorias (con relación de dependencia) y, por último, la incorporación del sistema de concursos del SINEP, a partir del año 2010 (posteriormente se expondrá la situación de este organismo en relación a su composición de personal según modalidad contractual y su evolución en ese periodo). En este organismo se realizaron cuatro concursos, en los años 2010, 2012, 2014 y 2015, para cubrir 300, 510, 307 y 1820 cargos, respectivamente (las bases de estas convocatorias se encuentran en las Resoluciones del Ministerio de Trabajo Nros. 670/10, 1045/12, 1504/13 y 
74/15). La elección del último de éstos, desarrollado en el año $2015^{9}$, respondió a dos factores. El primero, su dimensión: éste fue, por amplio margen, el más numeroso de todos los que se llevaron a cabo en la APN en aquellos años. El segundo fue de índole operativa: era el único de los cuatro concursos del cual se hallaban disponibles en la web las órdenes de mérito (los ganadores de los concursos), insumo fundamental de la investigación.

Respecto a la composición de personal de este organismo, según su modalidad contractual, pueden distinguirse dos grandes categorías:

- El personal permanente y transitorio.

- El personal contratado, que incluye los contratados sin relación de dependencia, Decreto $N^{\circ} 2.345 / 08$ (actualmente este sector se rige por el Decreto № 735/16), y con relación de dependencia, Decreto № 1.421/02 (contrataciones transitorias del Art. 9 de la Ley de Empleo Público).

Al indagar la evolución de cada categoría, tomando en consideración el periodo que comprende desde el inicio del proceso de regularización, año 2005 (en el que se produjeron los primeros traspasos de las contrataciones sin relación de dependencia aquélla otra que la tenía), hasta el año posterior al momento de ejecución de los concursos analizados, año 2016 (se toma el año posterior porque las gestiones que efectivizan el ingreso a planta permanente suelen insumir varios meses, cuando no años), en esta jurisdicción puede observarse que, mientras que la ocupación permanente y transitoria se incrementó casi un 24\% (de 1026 a 1269 integrantes), el personal contratado experimentó un salto exponencial de más del $1520 \%$ (de 195 a 3160 integrantes) $^{10}$. Al considerar el periodo más breve que inicia con la implementación de los concursos (año 2010) y llega hasta el 2016, el incremento de ambos grupos se equipara (29,75\% el primer grupo vs. $27,88 \%$ los contratados) (Tabla 1$)$. Al volcar los datos de la tabla en un gráfico que refleje la evolución de ambas variables, la situación resulta bastante elocuente (Gráfico 1). 
Tabla 1.

Evolución de la participación de contratados sobre el empleo permanente y transitorio en la Administración Central del Ministerio de Trabajo, Empleo y Seguridad Social entre los años 2005 y 2016

\begin{tabular}{lccc}
\hline Año & $\begin{array}{l}\text { Ocupación permanente } \\
\text { y transitoria }\end{array}$ & $\begin{array}{l}\text { Personal } \\
\text { contratado }\end{array}$ & $\begin{array}{l}\text { Porcentaje de contratados } \\
\text { sobre el total (\%) }\end{array}$ \\
\hline 2005 & 1026 & 195 & 15,97 \\
2006 & 988 & 936 & 48,65 \\
2007 & 986 & 1555 & 61,2 \\
2008 & 963 & 1940 & 66,83 \\
2009 & 987 & 2229 & 69,31 \\
2010 & 978 & 2471 & 71,64 \\
2011 & 948 & 2785 & 74,6 \\
2012 & 1137 & 2619 & 69,73 \\
2013 & 1127 & 2721 & 70,71 \\
2014 & 1076 & 3113 & 74,31 \\
2015 & 1058 & 3197 & 75,14 \\
2016 & 1269 & 3160 & 71,35 \\
\hline
\end{tabular}

Fuente: elaboración propia en base a los Boletines Fiscales de los años 2005 a 2016 (del $1^{\circ}$ Trimestre).

\section{Gráfico 1.}

Evolución de la Ocupación Permanente y Transitoria y del Personal Contratado en la Administración Central del Ministerio de Trabajo, Empleo y Seguridad Social entre los años 2005 y 2016

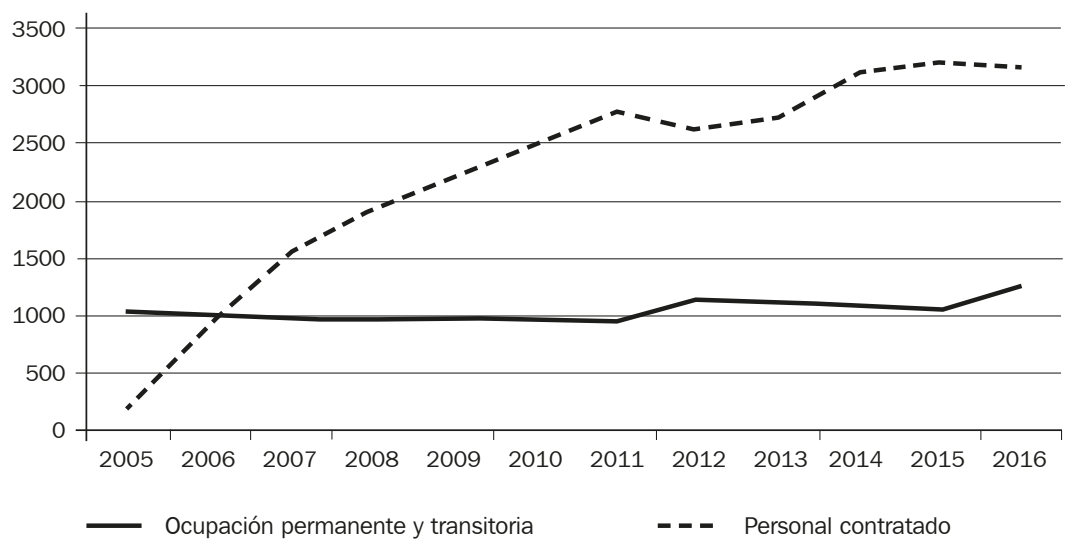

Fuente: elaboración propia en base a los Boletines Fiscales de los años 2005 a 2016 (del $1^{\circ}$ Trimestre). 
Respecto al peso de los contratados sobre el total del personal (permanente y transitorio más contratados), y su evolución en el periodo, puedan observarse las siguientes oscilaciones y tendencias. Al comenzar el proceso de regularización, año 2005, los contratados representaban el 16\%, porcentaje que fue ascendiendo ininterrumpida y aceleradamente hasta alcanzar, en el año 2011, el 74,6\%. Recién en el año 2012 se advierte un retroceso de este porcentaje, cayendo levemente por debajo del $70 \%$, sin duda por el paulatino traspaso a planta de los participantes del primer concurso, en el año 2010. Pero ya al año siguiente (2013) los contratados vuelven a experimentar un incremento, aunque leve, que se acentuará en los dos años posteriores (2014 y 2015). Recién en el año 2016 ese porcentaje retrocederá nuevamente, por el impacto de los concursos, incluido el del año 2015. Pero aún así ese porcentaje se mantuvo por encima del $70 \%$ (71,35\%).

\section{Gráfico 2.}

Evolución de la proporción de los Contratados sobre el empleo total en la Administración Central del Ministerio de Trabajo, Empleo y Seguridad Social entre los años 2005 y 2016

Porcentaje de contratados sobre el total (\%)

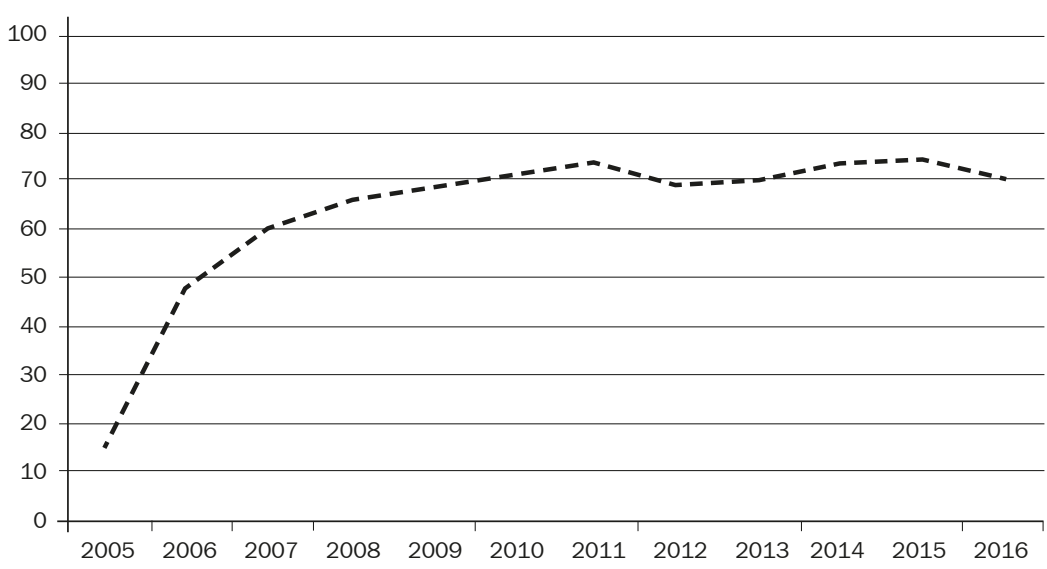

Fuente: elaboración propia en base a los Boletines Fiscales de los años 2005 a 2016 (del $1^{\circ}$ Trimestre). 


\section{7 aLGUNAS PRECISIONES METODOLÓGICAS}

En lo que respecta a la metodología empleada en la investigación cabe hacer las siguientes aclaraciones. La determinación de los ingresos (frente a las promociones y las regularizaciones), se llevó a cabo a través de los siguientes pasos. En primer término, se distinguió entre los procesos de selección enmarcados en convocatoria Abierta y aquellos otros sujetos a una convocatoria General (sólo para integrantes de la APN), lo cual consta en los Anexos I, II y III de la Resolución del Ministerio de Trabajo No 74/15. A continuación, y a través de las órdenes de mérito oficiales se obtuvo la nómina de ganadores de los concursos con convocatoria Abierta, obrantes en la página web oficial de este organismo (http://www.trabajo.gob.ar/concurso/merito_2015.asp). Posteriormente se indagó cuántos de estos casos registraban contrataciones vigentes al momento de los concursos o en los años previos (del año 2009 en adelante) en la APN. Con este fin se emplearon las siguientes fuentes:

- Publicaciones del Registro Central de Personas Contratadas de la ONEP (Oficina Nacional de Empleo Público), disponibles en la página web del Ministerio de Modernización ${ }^{11}$,

- Decretos y resoluciones que contenían designaciones especiales en la APN, que se extraen de la base de datos InfoLEG (Información Legislativa y Documental, http://www.infoleg.gob.ar/), del Ministerio de Justicia y Derechos Humanos de la Nación.

- La Resolución de reencasillamiento de personal del año 2009, Resolución Conjunta de la Secretaría de Gabinete y Gestión Pública, de la Jefatura de Gabinete de Ministros y el Ministerio de Trabajo, Empleo y Seguridad Social № 127.

Al delimitar los casos que registraban antecedentes o contratos vigentes en la APN dentro del total de los ganadores de los concursos, se puede establecer, por oposición, el número de ingresos efectivos y su peso relativo en ese total. A continuación se expondrán los resultados arrojados por la presente investigación. 


\section{RESULTADOS DE LA INVESTIGACIŌN}

Como se desprende de la Resolución del Ministerio de Trabajo. 74/15, que sienta las bases del proceso de concursos en cuestión, los mismos fueron para cubrir 1820 cargos. En el Anexo II y en la primera parte del III de dicha resolución constan los concursos que fueron por convocatoria Abierta, los cuales eran para cubrir 585 cargos (577 en el Anexo II, y 8 en el Anexo III).

De estos 585 cargos, sólo se registraron 77 cargos ganados por personas que no registraban antecedentes en la APN, según las nóminas mencionadas. Es decir, el porcentaje de ingresos es del $13,16 \%$ del total de cargos concursados con convocatoria Abierta.

Esta reducida apertura a la ciudadanía se acentúa si consideramos el número de personas (en lugar del número de cargos) sin antecedentes o contratos en la APN que ganaron estos concursos. Porque al considerar que existieron casos, dentro de estos 77 ganadores, de personas que ganaron más de un concurso (es decir, obtuvieron más de un cargo), obtenemos que esos 77 cargos fueron ganados por 62 personas.

Pero si consideramos el nivel de apertura a la ciudadanía, no puede pasarse por alto el hecho de que, si bien los concursos con selección abierta eran para cubrir 585 cargos, éstos se hallaban en el marco de un proceso de concursos para la cobertura de 1820 cargos. Es decir, los concursos abiertos eran para acceder al $32,14 \%$ de los cargos, mientras que para el $67,86 \%$ restante (1235) los concursos se restringían a quienes ya pertenecían a la APN (en otros términos, estos concursos se realizaron a través de convocatorias Generales). Esto iluminó otro aspecto del SINEP en relación a su nivel de apertura: la posibilidad de que participe en los concursos por convocatoria General el personal transitorio (Art. $9^{\circ}$ de la Ley de Empleo Público). Lo cual no deja de ser controvertido, ya que esta modalidad contractual, como se mostró, no brinda garantías suficientes contra la discrecionalidad. De este modo se estaría habilitando un mecanismo para ingresar a la planta permanente sin atravesar ninguna instancia de competencia abierta. En el caso de estos concursos, esto acabó ejerciendo un impacto negativo sobre la dimensión aquí analizada, ya que permitió incrementar el número de regularizaciones (en detrimento de los ingresos). Pero incluso más allá de estas situaciones particulares, puede concluirse que el nivel de apertura de la APN a la ciudadanía, en el caso del proceso de concursos analizado, es considerablemente bajo. 


\section{Gráfico 3.}

Cantidad de ingresantes sobre el total de los cargos concursados. Concursos de la Administración Central del Ministerio de Trabajo, Empleo y Seguridad Social, año 2015.

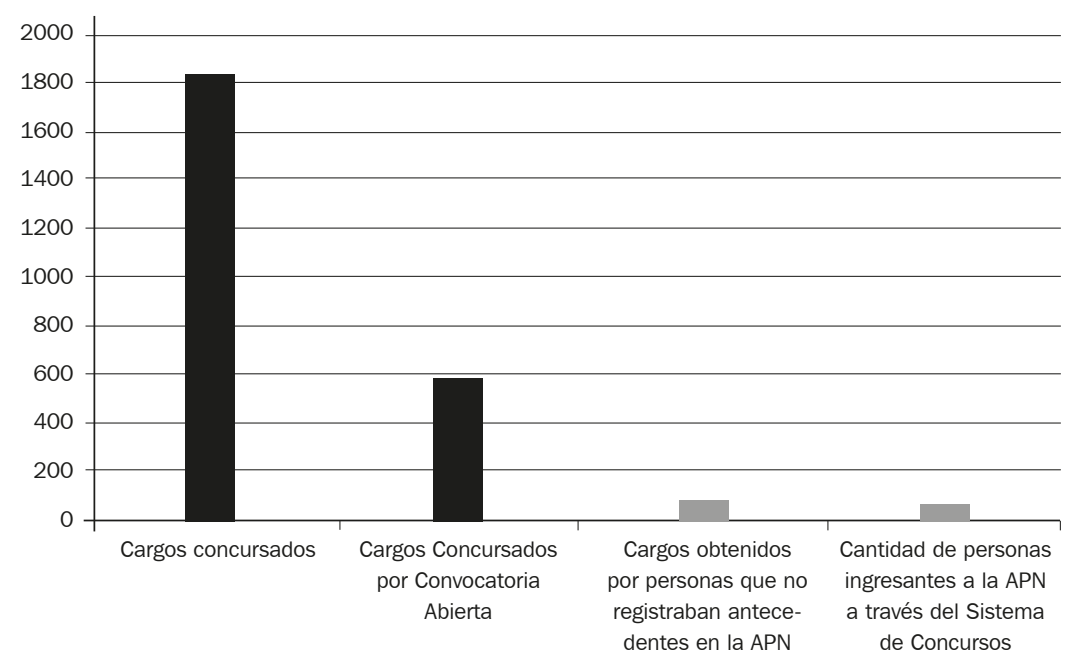

Fuente: elaboración propia a partir de la documentación mencionada.

\section{REFLEXIONES Y CONCLUSIONES}

Una conclusión que se impone, si consideramos que uno de los objetivos del SINEP era lograr un mayor nivel de apertura (algo que se puso de manifiesto al suprimir la Convocatorias Internas que contemplaba el SINAPA), es que claramente esto no se ha logrado aún. La mayor apertura formal no se tradujo, hasta aquí, en una mayor apertura «real». Esto significa, por otra parte, que solo en menor medida los concursos funcionaron como mecanismo de ingreso a la APN. Más bien lo hicieron como mecanismo de regularización y de promoción dentro del sistema de carrera.

En relación al patronazgo como fenómeno histórico, si bien no existe un modo univoco y directo de detectarlo y estimar su dimensión (de ahí la diversidad de metodologías con este propósito), fuertes indicios señalan su presencia en estas últimas décadas, como la suspensión de los concursos en el sistema de empleo previo, el SINAPA, y la proliferación posterior de las modalidades contractuales flexibles y transitorias. 
El presente trabajo muestra cómo también en la actualidad existe un importante indicio de la continuidad de esta práctica. Considerando que sólo los ingresos gozan de una "presunción" de ausencia de discrecionalidad (siendo ésta, como se ha argumentado, la máxima aproximación que puede hacerse al fenómeno en cuestión), el bajo nivel de apertura detectado constituye un claro indicio de la persistencia del patronazgo. Este indicio, sumado a los anteriores, contribuye a fundamentar la idea de su "arraigo".

Otra reflexión puede hacerse al vincular el bajo nivel de apertura con la información brindada en el apartado de composición de personal y su evolución a lo largo del periodo de ejecución de los concursos (entre los años 2010 y 2015). Como surge de la Tabla 1, en forma simultánea a la ejecución de los concursos se efectuaron 726 incorporaciones a través de las modalidades contractuales transitorias. Esto explica que los porcentajes del personal contratado (en torno al $70 \%$ ), no se redujera a pesar del traspaso a planta permanente generado por los concursos.

La convivencia de un bajo nivel de apertura con la continuidad de las modalidades contractuales transitorias pone de manifiesto un nuevo riesgo: que los concursos, en lugar de desplazar a este tipo de contrataciones (y a los mecanismos de ingreso que éstas suponen), se conviertan en un medio de regularización generalizado de estas contrataciones, resignando en gran medida su condición de mecanismo de ingreso (el único con garantías de una efectiva igualdad de oportunidades).

En este sentido, la categoría de nivel de apertura revela su utilidad. Al distinguir las funciones que cumplen los concursos (promociones, regularizaciones e ingresos) permite estimar el peso de cada una de éstas. De este modo, brinda la posibilidad de detectar esta dinámica (de continuidad de contrataciones transitorias y uso sistemático de los concursos como mecanismo de regularización), contribuyendo a impedirla. 


\section{NOTAS}

${ }^{1}$ El presente artículo se basa en un trabajo de investigación desarrollado en la Universidad de Quilmes, dirigido por la Dra. Mercedes Llano. El autor agradece a los evaluadores, cuyas correcciones y comentarios permitieron dar mayor cohesión y solidez al trabajo.

2 Del célebre art. 6 de la Declaración de los Derechos del Hombre y el Ciudadano de 1789 se desprendía la aspiración irrestricta de la ciudadanía a competir por todos los cargos públicos, "sin otra distinción que la de sus virtudes y sus talentos". Longo (2004: 70) declara al respecto: "La histórica fórmula combina los dos pilares sobre los que se fundará la identidad de la FP: la igualdad y el mérito".

${ }^{3}$ La AP en Argentina se compone de tres niveles de gobierno (nacional, provincial y municipal), y tres poderes (ejecutivo, legislativo y judicial, éste último sólo en los dos primeros niveles de gobierno). El Sistema de Empleo Público mencionado incluye, dentro de la Administración Central de la APN argentina, al personal del Poder Ejecutivo Nacional, excluyendo a las Fuerzas Armadas y de Seguridad, y a numerosos Organismos Descentralizados (AFIP, ANSES, etc.), que se rigen mayoritariamente por la Ley de Contrato de Trabajo, Ley $N^{\circ} 20.744$. Tampoco incluye a aquel personal que se rige otras modalidades contractuales, como los Regímenes de Contrataciones Temporales de Servicios Personales Autónomos. ${ }^{4}$ Información obtenida del Boletín Fiscal del $2^{\circ}$ Trimestre del 2005. https://www.minhacienda. gob.ar/onp/documentos/ boletin/2dotrim05/ 2dotrim05.pdf

5 Respecto a los requisitos exigidos en las contrataciones flexibles (las vigentes en el periodo en el que se realizaron los concursos), véase el Decreto $N^{\circ} 2345 / 08$, arts. 1, 3, 10 y 11; y a las transitorias, el Decreto No 1421/01, art. 9, Inc. b, la Resolución de la Subsecretaría de Gestión y Empleo Público, arts. 2 a 9, el Decreto No 214/06, Anexo I, art. 11.

${ }^{6}$ Previo descongelamiento de los cargos vacantes de la planta permanente (lacoviello y Llano, 2015: 6), establecidos por el art. 7 de la Ley $26.337 / 07$, y el art. $7^{\circ}$ de la $26.422 / 08$. Pos- teriormente las Decisiones Administrativas de la Jefatura de Gabinete de Ministros Nros. 506/09, 1126/12 y 609/14 autorizarían la cobertura de 1000, 5000 y 7500 cargos respectivamente.

7 La Decisión Administrativa de la Jefatura de Gabinete de Ministros Nº 609/14, no sólo asume abiertamente la posibilidad de esta función (de cambio de modalidad contractual), sino que prioriza la convocatoria a concursos (para el ingreso a planta permanente) de los cargos ocupados por designaciones transitorias (en su art. 11, sostiene que "Los cargos de Planta Permanente que hubieran sido objeto de designaciones transitorias, con exclusión de aquéllos con funciones ejecutivas, gerenciales o equivalentes, deberán ser puestos en convocatoria para su cobertura definitiva mediante el correspondiente proceso de selección...").

8 El alcance de las convocatorias Abiertas se define a partir de criterios como el agrupamiento (General, Profesional, Científico-Técnico y Especializado), el nivel (categorías que oscilan entre la $F$ y la A), la naturaleza de ciertas funciones (las ejecutivas), y las vacantes no cubiertas en convocatorias Generales (art. 44).

${ }^{9}$ Su marco normativo fue el siguiente: la Decisión Administrativa de la Jefatura de Gabinete de Ministros No 609/14 autorizó la cobertura de 7500 cargos vacantes de la planta permanente del SINEP, correspondiente al Ejercicio Presupuestario 2014, y la Resolución de la Secretaría de Gabinete y Coordinación Administrativa No 646/14 asignó al Ministerio de Trabajo 1.820 de esos cargos vacantes. Con posterioridad, la Resolución del Ministerio de Trabajo No 1371/14 dio inicio formal a los procesos de selección, designando a los integrantes de los Comités de Selección y asignando facultades a la Subsecretaría de Coordinación del Ministerio de Trabajo para la implementación de los mismos. Por último, la Resolución No 74/15 de esta misma cartera de Estado aprobaría las Bases dictadas por dichos Comités de Selección, y llamaría a Concurso mediante Convocatoria Extraordinaria, detallando en los Anexos adjuntos los cargos sujetos a Convocatoria General y a Convocatoria Abierta, 
estableciendo fecha, sede y horario de inscripción electrónica y documental, y presentando un cronograma tentativo de las etapas del proceso de concursos.

10 La información fue extraída de los Boletines Fiscales de los años 2005 a 2016 (del $1^{\circ}$ Trimestre).
11 Nómina del Personal con Contratos vigentes durante el mes 12/2015 correspondiente al organismo. Registro Central de Personas Contratadas, Secretaría de Empleo Público, Ministerio de Modernización.

http://www.sgp.gov.ar/sitio/empleo/regimenes/ contratados/listadocontratados/todos_los_contratos_anuales/index_main_rcpc.html

\section{BIBLIOGRAFÍA}

Dieguez, G. y Gasparin, J. (2016). El rompecabezas del empleo público en Argentina: ¿Quiénes hacen funcionar la maquinaria del Estado? Documento de Políticas Públicas. CIPPEC.

DNSC (Dirección Nacional de Servicio Civil) (2013b). Reporte Estadístico Mensual de Alta Dirección Pública (febrero). Santiago de Chile: DNSC. Disponible en http://www.serviciocivil. gob.cl/reporte-estad\%C3\%ADstico-mensual-dealta-direcci\%C3\%B3n-p\%C3\%BAblica.

Dussauge Laguna, M. (2005). Servicio civil de carrera o servicio civil de empleo? Una breve discusión conceptual. Revista Servicio Profesional de Carrera. (No 3).

Evans, P. y Rauch, J. (1999). Bureaucracy and Growth: A Cross-National Analysis of the Effects of Weberian. State Structures on Economic Growth. American Sociological Review, Vol. 64, No 5: 748-765.

Ferraro, A. (2006). Una idea muy precaria. El Nuevo Servicio civil y los viejos designados políticos en Argentina. Latin American Research Review, Vol. 41, № 2 (junio): 165-182.

Geddes, B. (1996). Politician's Dilemma. Building State Capacity in Latin America. Estados Unidos: University of California Press.

Grindle, M. (2012). Job for the boys. Patronage and the State in Comparative Perspective. Harvard University Press.

lacoviello, M. (1996). El juego político y las estrategias de recursos humanos en las organizaciones públicas. Cuaderno CEPAS No 4

(2006). Análisis comparativo por subsistemas. En Koldo Echabarría (ed.). Informe sobre la situación del Servicio Civil en Latinoamérica. Washington DC: BID: 531-572.

lacoviello, M. y Pando, D. (2015). La administración pública en Argentina: caracterización y análisis de su dinámica político-institucional. En Alba, Carlos y Peters, Guy (eds.). Handbook of Public Administration and Civil Service in Latin America (en prensa). 
lacoviello, M. y Zuvanic, L. (2006). Síntesis del diagnóstico Caso Argentina. En Echebarría, Koldo (ed.). Informe sobre la situación del Servicio civil en Latinoamérica. Washington DC: BID: 73-96.

(2008). Gestión pública en América Latina: vuelos innovadores y pistas de aterrizaje. XIII Congreso Internacional del CLAD sobre la Reforma del Estado y de la Administración Pública, Buenos Aires, Argentina, 4 al 7 noviembre.

Iacoviello, M., Pando, D. y Llano, M. (2013). Modalidades de empleo, modelos de gestión y tipos burocráticos: la diversidad como regla en la función pública argentina. XVIII Congreso Internacional del CLAD sobre la Reforma del Estado y de la Administración Pública, Montevideo, Uruguay, 29 oct. -1 nov. 2013

lacoviello, M. y P. Amaya (2009). Diagnóstico institucional del Sistema de Servicio Civil. Evaluación final del Programa de Fortalecimiento de la Dirección Nacional de Servicio Civil. Washington, D.C.: BID, Gobierno de Chile.

Llano, M. (2017). Explorando herramientas para analizar el nivel de profesionalización de los sistemas de empleo público municipales. Ponencia preparada para el XIII Congreso Nacional de Ciencia Política "La política en entredicho. Volatilidad global, desigualdades persistentes y gobernabilidad democrática", organizado por la Sociedad Argentina de Análisis Político y la Universidad Torcuato Di Tella, Buenos Aires, 2 al 5 de agosto de 2017.

(2016). «Expresiones comunes del patronazgo: un fenómeno sin épocas ni fronteras", DAAPGE, año 16, № 27 (jul-dic), 2016, pp. 129-160. Santa Fe, Argentina: UNL.

(2015). Burocracia pública y sistema político en América Latina. Factores asociados a la politización de los sistemas de gestión de empleo público en la región. Tesis Doctoral. Universidad Complutense de Madrid.

Llano, M. y lacoviello, M. (2015). Confianza mata mérito: el impacto de la concentración de poder presidencial en la gestión de recursos humanos en el Estado argentino. Ponencia preparada para el XII Congreso Nacional de Ciencia Política, organizado por la Sociedad Argentina de Análisis Político y la Universidad Nacional de Cuyo, Mendoza, 12 al 15 de agosto de 2015

Llano, M.M. (2014a). Diagnóstico institucional del servicio civil en América Latina: Brasil. BID: en línea: http://publications.iadb.org/bitstream/handle/11319/6623/Diagn\%C3\%B3stico\%20 institucional\%20\%20del\%20senvicio\%20civil\%20en\%20\%20Am\%C3\%A9rica\%2OLatina-\%20 Brasil.pdf?sequence $=1$.

Longo, F. (2006). Una lectura transversal de los resultados. En Echebarría, K. (ed.). Informe sobre la situación del Servicio civil en Latinoamérica. Washington DC: BID: 593-610.

López, A. y Zeller, N. (2010). Argentina: un balance de las reformas administrativas en el Estado Nacional a 25 años de Democracia. Serie Desarrollo Institucional y Reforma del Estado. Dirección de Investigaciones, INAP. Documento de Trabajo № 1. 
Pomares, J., Gasparin, J. y Deleersnyder, D. (2013). Evolución y distribución del empleo público en el sector público nacional argentino. Una primera aproximación. Documento de Trabajo No 117.

Portales, C. (2009). Estudio sobre estatuto administrativo, remuneraciones y calificaciones en el personal del gobierno central de Chile. Un mejor Estado para Chile. Santiago de Chile: Consorcio para la Reforma del Estado.

Ramió, C. y Salvador, M. (2005). Instituciones y Nueva Gestión Pública en América Latina. Barcelona: Fundació CIDOB.

Remmer, K.L. (2007). The Political Economy of Patronage: Expenditure Patterns in the Argentine Provinces, 1983-2003. The Journal of Politics, Vol. 69 (2), 363-377.

Salas, E. (2015). Una larga marcha hacia la consolidación del ingreso y promoción por concursos en el Sistema Nacional de Empleo Público de Argentina. XX Congreso Internacional del CLAD sobre la Reforma del Estado y de la Administración Pública, Lima, Perú, 10-13 nov. 2015

Salas, E. y Wegman, M. (2014). Para el Servicio civil que merece un país en serio. Hacia la consolidación del derecho de igualdad de todo ciudadano a ingresar a la Administración Pública por concursos de méritos y capacidades. Cuaderno de Administración № 1 AAEAP (Asociación Argentina de Estudios de Administración Pública).

Salas, E. (2010). Modernización del Empleo Público Federal Argentino: Negociación Colectiva y Mejora en la Calidad de los Servicios Públicos. Seminario Internacional. Innovación y calidad en la Administración Pública, una perspectiva para el desarrollo sostenible de nuestras naciones. XV Foro de la Función Pública de Centroamérica.

Schedler, A. (2004). El voto es nuestro. Cómo los ciudadanos mexicanos perciben el clientelismo electoral. Revista Mexicana de Sociología, Año 66, №1, (enero-marzo): 57-97.

Scherlis, G. (2012). Designaciones y organización partidaria: el partido de redes gubernamentales en el peronismo kirchnerista. América Latina Hoy, Vol. 62: 47-77.

(2009). Patronage and Party Organization in Argentina: The Emergence of the Patronage-based Network Party. Tesis Doctoral, Universidad de Leiden.

(2013). The contours of party patronage in Argentina. Latin American Research Review, Vol. 48, No 3. (C) 2013 by the Latin American Studies Association

\section{PARA CITAR ESTE ARTÍCUL0:}

Luxardo, D. (2019). "El patronazgo en los tiempos del sistema nacional de empleo público (SINEP) de la APN de la República Argentina. Nuevos escenarios de un lastre atávicon, DAAPGE, año 19, № 32 (enejun), 2019, pp. 173-196. Santa Fe, Argentina: UNL. 